TI 2018-075/IV

Tinbergen Institute Discussion Paper

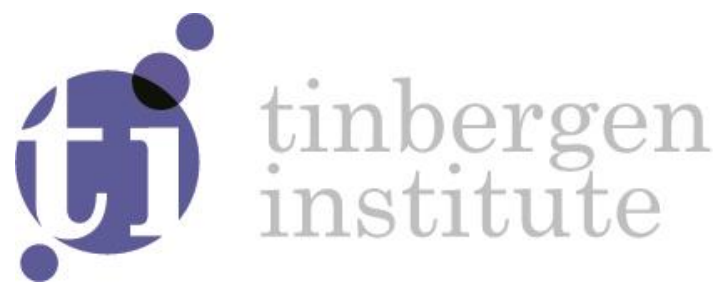

\title{
Income Inequality and Stock Market Returns
}

\author{
Agnieszka (A.P.) Markiewicz ${ }^{1}$ \\ Rafal Raciborski
}

${ }^{1}$ Erasmus University Rotterdam

2 European Commission 
Tinbergen Institute is the graduate school and research institute in economics of Erasmus University Rotterdam, the University of Amsterdam and VU University Amsterdam.

Contact: discussionpapers@tinbergen.nl

More TI discussion papers can be downloaded at http://www.tinbergen.nl

Tinbergen Institute has two locations:

Tinbergen Institute Amsterdam

Gustav Mahlerplein 117

1082 MS Amsterdam

The Netherlands

Tel.: +31(0)205984580

Tinbergen Institute Rotterdam

Burg. Oudlaan 50

3062 PA Rotterdam

The Netherlands

Tel.: +31(0)10408 8900 


\title{
Income Inequality and Stock Market Returns*
}

\author{
Agnieszka Markiewicz ${ }^{\dagger}$ \\ Erasmus University Rotterdam \\ Tinbergen Institute
}

\author{
Rafal Raciborski ${ }^{\ddagger}$ \\ European Commission \\ Vistula School of Economics
}

July, 2018

\begin{abstract}
In this paper, we study the relationship between income inequality and stock market returns. We develop a quantitative general equilibrium model that links shifts in both labour and capital income inequality to stock market variables. An increase of the share of capital owners' income from risky capital leads to higher equity premium and a rise in their non-risky, labor share of income reduces it. When we calibrate our model to match the empirical size of shifts in the last five decades, we find that the negative impact of the higher labour share of income of capital owners dominates and brings the equity premium below the historical value by 0.79 percentage points, in line with the data. If both capital and total income shares of top decile would continue growing at the historical rate between 1970 and 2014, the equity premium would continue decreasing to $6.11 \%$ in 2030 , 0.92 percentage point lower than historical equity premium of $7.03 \%$. If instead only the capital share of income continues to grow, the equity premium would be higher than the historical average by 0.57 percentage point. If the labour income dispersion remains constant, the historical equity premium of $7.03 \%$ would be reached by 2030 if the capital share of income was growing by $1.4 \%$ each year.
\end{abstract}

Keywords: Asset Pricing, Risk Premium Dynamics, Income Inequality, Computational Macroeconomics.

JEL Classification: D31, E32, E44, H21, O33.

\footnotetext{
*For helpful comments and suggestions we thank Bünyamin Erkan, Kevin Lansing, Andreas Pick, Vincent Rebeyrol and participants of the 25th Society of Nonlinear Dynamics and Econometrics meeting in Paris, Fifth International Symposium in Computational Economics and Finance in Paris, Society of Economic Dynamics meeting in Edinburgh, Fifth International Symposium in Computational Economics and Finance in Paris and National Bank of Poland workshop in Warsaw.

${ }^{\dagger}$ corresponding author: Erasmus University Rotterdam, P.O. Box 1738, 3000 DR Rotterdam, the Netherlands, markiewicz@ese.eur.nl

${ }^{\ddagger}$ The content of this study does not reflect the official opinion of the European Union. Responsibility for the information and views expressed in the paper lies entirely with the author.
} 


\section{Introduction}

Equities are concentrated in the hands of households at the top of the U.S. income distribution. ${ }^{1}$ One might therefore expect that changes in their labor and capital incomes affect the movements in asset prices. Both labor and capital shares of income of the U.S. richest households increased during the last five decades, which was accompanied by large shifts in returns from risky assets. The equity premium, which was as high as $9 \%$ during the first 25 years after the war, dropped to below $6 \%$, on average, since the early 1970s. In this paper, we study the relationship between income inequality and stock market returns. We develop a general equilibrium model that links shifts in both labour and capital income inequality to stock market variables and investigate in how far these shifts could explain the fall in equity returns.

Our model includes two groups of agents. The top income group (capital owners) owns $100 \%$ of the economy's financial wealth - a setup that roughly approximates the highly-skewed distribution of U.S. financial wealth. ${ }^{2}$ The rest of the economy is populated by workers who consume their labor income and income from risk-free government and corporate bonds. This set-up is similar to Greenwald et al. (2016). The key difference of our model is that, in addition to the capital income, capital owners earn labor income, in line with empirical observation that the top wealth holders of today are also the top earners. Saez and Zucman (2016) show that in 2012 the top $0.1 \%$ of wealth holders earned 31 times the average labor income and their pre-tax income share almost tripled between 1960 and 2012.

Our model provides a simple intuition on how shifts in income inequality, as measured by changes in income shares, affect asset pricing variables and, in particular, the equity premium. An increase in the share of risky capital in income and, hence, in consumption of capital owners leads to a higher equity premium. The opposite is true when the share of non-risky labor income in the total income of capital owners rises. However, according to the data, capital owners benefited from increase in both incomes over the last four decades. As a result, the total quantitative impact of income inequality shifts on the stock market return is unclear. ${ }^{3}$

We build a quantitative model that allows us to assess the impact of the joint

\footnotetext{
${ }^{1}$ Chen and Stafford (2016) argue that even fewer than 20 percent of households own stock directly.

${ }^{2}$ The share of total financial wealth owned by the top $10 \%$ of households is around $80 \%$ in the sample period (Wolf, 2010).

${ }^{3}$ The total share of income of capital owners or, equivalently in our model, top decile earners, in the U.S. increased from $32 \%$ to $47 \%$ between 1970 and 2014 as shown in Figure 1, top panel. Both, top decile labor and capital shares increased during this period as shown in Figure 2.
} 
increases in capital and labor income shares of the top decile of the U.S. income distribution on the stock market. The model extends the standard RBC setting used in the production-based (CCAPM) literature allowing for heterogeneity of agents, which differ by their ability to hold financial assets and having different output elasticities of labor. This set-up turns out sufficient to broadly match both, stock market and real economy statistics.

The source of macroeconomic risk in the model is a standard technology shock. The model delivers high mean equity premium and realistic Sharpe ratio via a combination of three factors. First, to generate a high price for risk, following Greenwald et al. (2016), we introduce high and time-varying coefficient of risk-aversion in capital owners' utility function. Second, capital is subject to adjustment costs in the spirit of Uhlig (2007) and Jermann and Quadrini (2012). Finally, financial leverage of firms increases the quantity of risk borne by capital owners thus helping to generate a realistic Sharpe ratio. Careful calibration of these channels allows for precise matching of the mean and standard deviation of equity premium (and hence the Sharpe ratio), which has proven a challenge in models that use other mechanisms. Additionally, introducing financial leverage pins down the non-zero rate of risk-free savings on the side of consumers, which increases the realism of the model.

We calibrate the model to the U.S. post-war economy when the equity premium of S\&P500 shares reached $7.03 \%$. In order to gauge the quantitative impact of changes in income inequality on the equity premium, we carry out three counterfactual scenarios. First, we consider an increase in capital income inequality and change the value of capital share of income, from its baseline value of 0.28 to 0.34 , its empirical value in 2014. This increase leads to the mean equity premium that is higher by 0.43 percentage points than the historical average.

Second, we raise the value of the labour share of income of top decile from $3.5 \%$ to $13 \%$, its 2014 value. We show that the steady increase of the capital owners' labour share between 1970 and 2014 should have exercised a strong downward pressure on the equity premium. In fact, the model predicts that if there was no increase in capital income inequality, but only in labour income, the equity premium would have been lower by 1.64 percentage points.

Finally, considering the two changes together, we show that the net effect on the equity premium is negative, in line with what has been observed in the S\&P500 data. The reason is that, capital owners benefited from a faster growth in their non-risky labour income share relative to the risky capital income share bringing the equity 
premium below the historical value by 0.79 percentage points.

Next, we construct scenarios for the size of the equity premium in 15 years from now, assuming that the U.S. income inequality continues increasing. We consider two different scenarios for future trends in income inequality and introduce them into the model to derive the equity premium response.

The first scenario assumes that both capital and total income shares of the top decile will grow at the same rate as between 1970 and 2014 until 2030, namely $0.5 \%$ and $0.92 \%$, respectively. In this case, we find that the equity premium would continue decreasing to $6.11 \%$ in $2030,0.92$ percentage point lower than historical average. In the second, more likely scenario, we assume that the labour share of income of capital owners stops growing and only capital share of income continues to increase. ${ }^{4}$ If capital share of income continues to grow at the annual rate of $0.5 \%$ and the labour share of income of top decile remains unchanged, capital would represent $37 \%$ of total income in the U.S. in 2030. Total income of top decile would amount to half of the income in the U.S. economy. In this scenario, the equity premium would be higher than the historical average by 0.57 percentage point.

Finally, we use the model to perform a reverse engineering exercise, in which we compute the income inequality required to reach the post-war average equity premia of $7.03 \%$ and $9.07 \%$, starting from today's values. We make predictions about the behavior of one of the shares of income and compute a change in the other share required to match historical equity premium. If the labour income dispersion stops increasing, the historical equity premium of $7.03 \%$ would be reached by 2030 if capital share of income was growing by $1.4 \%$ each year, consistent with Piketty's (2014) predictions. If the equity premium was instead, to reach its value from immediately after the war of $9.07 \%$, the capital share of income would need to grow at the annual $4.31 \%$ until 2030, an unlikely scenario.

The model developed here builds on the literature embedding risky asset markets into RBC models, as proposed by Jermann (1998), Boldrin et al (2001) and Danthine and Donaldson (2002). Guvenen (2009) and Guvenen and Kuruscu (2006) introduce into an otherwise standard RBC framework two types of consumers, which differ by their elasticity of intertemporal substitution. The latter element differentiates these

\footnotetext{
${ }^{4}$ This assumption is motivated by observation that since 2000 , the labour income inequality has not been increasing. In contrast, capital share of income started rising since 2000. These trends are in line with the literature on skill-biased technological change which is commonly thought to have initially driven income inequality and generated higher dispersion in savings from labour income and higher capital income inequality. See also Saez and Zucman (2016) for empirical support of this hypothesis.
} 
papers from our approach, in which we assume that the preferences of our two types of consumers are identical.

Our paper is probably most closely related to Lansing (2015) who, in an RBC setting, studies the consequences of short-term fluctuations in the capital income distribution. However, similar to the other papers mentioned above, the goal of Lansing (2015) is to explain the high post-war equity premium. In contrast, in this paper we focus on the longer-term, structural shifts in income shares and we link them to long-term trends observed in the equity premium and in particular its recent decline. Finally, we share the interest in the longer-term trends in income shares and their consequences for equity markets with Greenwald et al. (2016). Our modelling strategy largely benefited from their set-up, namely, we use their risk aversion shock specification to deliver a sizeable average equity premium. Unlike in Greenwald et al. (2016), however, in our model capital owners are also high labour income earners. The latter element turns out to be crucial for explaining a part of the observed downward trend in the average equity premium.

By studying the link between income shares and asset returns, we also contribute to the fast-growing literature emphasizing the importance of wealth dispersion and resulting capital income inequality in the U.S. and other developed economies. Kacperczyk et al. (2016) show that capital income inequality is large and growing fast, accounting for a considerable portion of total income inequality in the U.S. In addition, Saez and Zucman (2016) demonstrate an increased correlation between top labor and top capital incomes in the U.S. data. Our framework is motivated by these resent empirical observations and therefore models capital owners also as high labor income earners.

The paper is organized as follows. In Section 2, we describe a set of stylized facts on changes in income inequality and equity premium. In Section 3, we describe the model and its main intuition. Specifically, we explain the mechanisms generating high equity premium and Sharpe ratio and how they respond to shifts in income shares. In this section, we also describe our calibration strategy. Section 4 evaluates the quantitative performance of the model in both macroeconomic and financial dimensions. In Section 5, we carry out a set of counterfactual exercises which allow us to assess the quantitative impact of the recent increase in income inequality on the equity premium. In this section, we also implement a number of scenarios for future behavior of equity premium based on the income inequality predictions. Section 6 concludes. 


\section{Income Inequality and Asset Pricing Variables in the Data}

\subsection{Capital and labor shares of income}

The recent increase of income inequality has been accompanied by rising capital share of income. Karabarbounis and Neiman (2014) show that the labour share of income has significantly declined since the early 1980 s in the large majority of countries, including the U.S.

Figure 1: Top decile income share and capital share of income in the U.S.
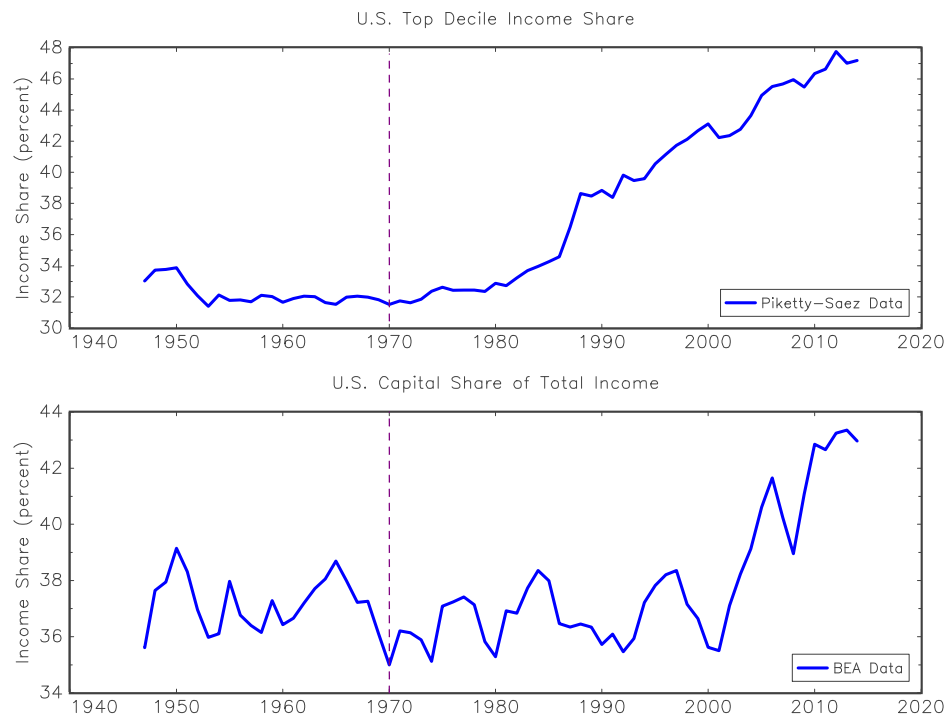

Top decile income share series comes from the World Inequality Database at https://wid.world/. Capital share of income is computed from Bureau of Economic Analysis database as 1-compensation of employees.

Figure 1 plots increase in the top decile and capital shares of income in the U.S. There is a clear positive trend in both series. Capital share of income increased from $35 \%$ to $43 \%$ between 1970 and 2014 and the top decile income share raised from $32 \%$ to $47 \%$ during the same period. Given that the capital stock is concentrated in hands of a relatively small group of wealthy households, the observed increase in capital share of income directly implied an increase in income inequality. While total labor share of income declined in U.S. in the recent decades, the relative labor share of top incomes increased as well.

Figure 2 plots the composition of the top decile income share in the U.S. between 
Figure 2: Top decile income share and its composition between 1970 and 2011

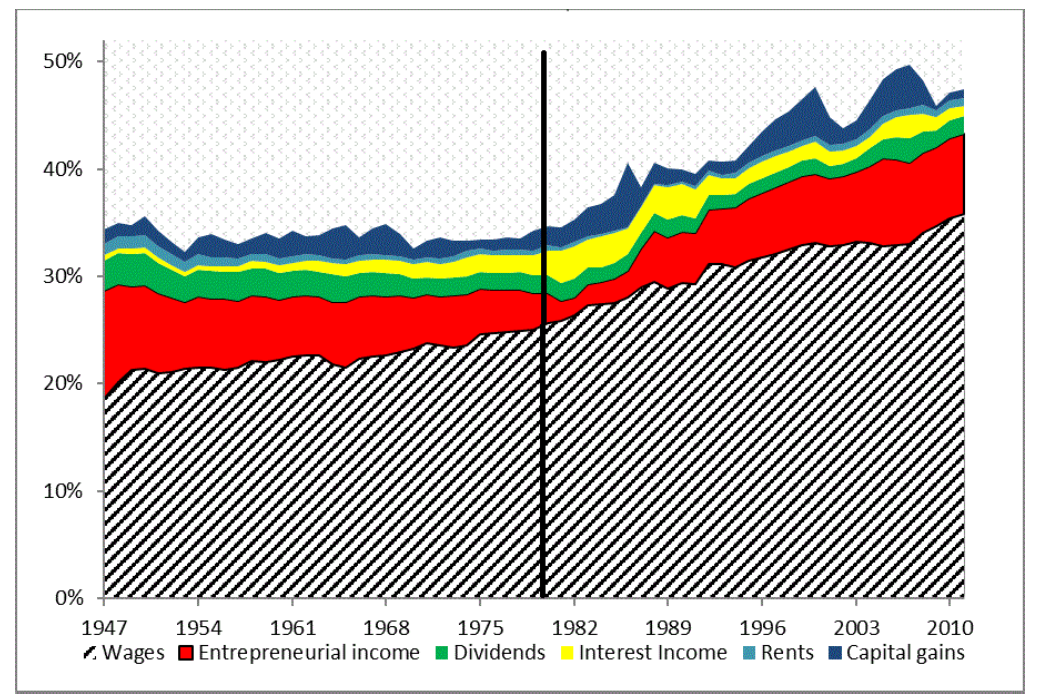

The solid area shows capital share of income and its composition: capital gains, rents, interest income, dividends and entrepreneurial income. Striped area shows labor share of income which covers wages and salaries, bonuses, exercised stock-options, and pensions. The figures are computed as shares of total U.S. income. Income share data is described in Atkinson et al. (2011) and can be found at https://wid.world/ 
1947 and 2011. The striped area of the figure corresponds to the labor income and demonstrates that its share increased during the past thirty years from $25 \%$ to $33 \%$ of total income in the U.S. economy. The solid area shows how capital gains, rents, interest rates, dividends, and business income evolved during this period. These components are combined to form one category: capital share of income, which also increased during the last three decades. It represented $8.9 \%$ of top decile income share in 1980 and $13 \%$ in 2011.

Top incomes thus experienced an increase from both sources: capital and labor and, there is in fact, a strong positive correlation between top labor and capital incomes. The top wealth holders of today are also the top earners. ${ }^{5}$

\subsection{Equity premium}

While income inequality increased during the last five decades the equity premium has decreased. In Table 1, we report the figures for the equity premium computed form the Shiller's website: http://www.econ.yale.edu/ shiller/data.htm. The first column denotes the period over which the statistic was computed. In the second column, we show the values for the equity premium (EP) and in the third column for Sharpe ratios (SR). The first row shows that the equity premium reached $7.03 \%$ on average during the post-war period while Sharpe ratio was equal to 0.43 during the same period.

Table 1: Equity premium and Sharpe ratio for SP 500

\begin{tabular}{llc}
\hline & EP & SR \\
\hline $1947-2014$ & $7.03 \%$ & 0.43 \\
$1947-1970$ & $9.07 \%$ & 0.59 \\
$1971-2014$ & $5.92 \%$ & 0.34 \\
\hline
\end{tabular}

EP stands for equity premium and SR for Sharpe ratio. Both statistics are computed using the annual data from Shiller's website: http://www.econ.yale.edu/ shiller/data.htm. Equity premium is computed as the difference between the return including dividends on S\&P 500 and the risk free rate is 6 months rolled commercial paper rate.

The following two rows report the statistics for the period before 1970 and after 1970. The equity premium before 1970 was a third higher than after 1970. In case

\footnotetext{
${ }^{5}$ As previously mentioned, there is an increasing evidence that top labor and top capital incomes are strongly correlated. For instance, Saez and Zucman (2016) show that in 2012 the top 0.1\% of wealth holders earned 31 times the mean labor income.
} 
of the Sharpe ratio statistics, this pattern is even stronger as the value before 1970 is almost twice as high as after 1970 .

\section{Model}

As our analytical tool we build on the model by Lansing and Markiewicz (2018). The model extends the standard RBC setting used in the production-based Consumption Capital Asset Pricing Model (CCAPM) literature allowing for two types of agents differing by their ability to hold financial assets and who face different output elasticities of the labor they provide. This extension to the standard framework lets us trace the impact of the shifts in the capital share and labor-income shares on the stock market price behavior and, in particular, on the mean equity premium.

There are several additional elements of the model worth emphasizing. The high mean equity premium and realistic Sharpe Ratio obtained in our setting are due to a combination of three factors: (i) time-varying coefficient of risk aversion, as in Greenwald et al. (2016), which increases the price for risk in the economy; and (ii) capital adjustment costs and (iii) financial leverage, which both increase the quantity of risk borne by the agents investing in stocks. Careful calibration of these channels allows for precise matching of the mean and standard deviation of equity premium (and hence the Sharpe Ratio), which has proven a challenge in models that use other mechanisms to generate high equity premium. ${ }^{6}$ Additionally, introducing financial leverage pins down the non-zero rate of risk-free savings on the side of consumers, which increases the realism of the model. ${ }^{7}$

\subsection{Workers}

Workers, of mass $1-\eta$, maximize a discounted sum of utility over consumption, $c_{t}^{w}$ :

$$
\max _{c^{w}, a^{f}, a^{c}} E_{0} \sum_{t=0}^{\infty} \beta_{t}^{w} \frac{\left(c_{t}^{w}\right)^{1-\gamma^{w}}}{1-\gamma^{w}},
$$

\footnotetext{
${ }^{6}$ This literature is too broad to be discussed here. For an early account of the puzzle in a framework with fully-fledged production see, e.g., Jermann, 1998. It is worth emphasizing that there is typically a trade-off between fitting the asset market and real-economy statistics and that it is not possible to fit exactly both sets of statistics in our model. This observation is of general nature, however, and holds for many modern production-based CCAPMs (e.g. Guvenen, 2009).

${ }^{7}$ As is well known, in this class of models, due to the Euler equation that does not contain quantities, the prevailing risk-free rate of return is consistent with an arbitrary asset portfolio composition. A zero-risk-free saving rate is, therefore, usually assumed in these models.
} 
where $\beta_{t}^{w}$ is an individual worker's discount factor and $\gamma^{w}$ is her coefficient of risk aversion. The maximization is subject to a budget constraint:

$$
c_{t}^{w}+a_{t}^{f} P_{t}^{f}+a_{t}^{c, w} P_{t}^{c}=W_{t}^{w} n_{t}^{w}+a_{t-1}^{f}+a_{t-1}^{c, w},
$$

with $W_{t}^{w}$ the wage rate received by workers, $P_{t}^{f}$ and $P_{t}^{c}$ the prices of zero-supply risk-free bonds and (risk-free) corporate bonds, respectively, and $a_{t}^{f}$ and $a_{t}^{c, w}$ the respective positions taken by workers in these assets. Workers are assumed to incur a transaction cost for trading stocks which prohibits their participation in stock exchange. ${ }^{8}$ Finally, $n_{t}^{w}=n^{w}$ is the constant supply of labor hours per worker.

Assuming the usual transversality condition, first order conditions for the worker's problem are standard:

$$
\begin{gathered}
\left(c_{t}^{w}\right)^{-\gamma^{w}}=\lambda_{t}^{w} \\
1=\beta_{t}^{w} E_{t} \frac{\lambda_{t+1}^{w}}{\lambda_{t}^{w}} R_{t}^{f} \\
1=\beta_{t}^{w} E_{t} \frac{\lambda_{t+1}^{w}}{\lambda_{t}^{w}} R_{t}^{c}
\end{gathered}
$$

with $\lambda_{t}^{w}$ the worker's marginal utility of consumption and $E_{t}$ representing the mathematical expectation operator conditional on information at the end of period t. By definition, the returns on risk-free assets satisfy:

$$
\begin{aligned}
& R_{t}^{f}=\frac{1}{P_{t}^{f}} \\
& R_{t}^{c}=\frac{1}{P_{t}^{c}}
\end{aligned}
$$

By construction we also have $R_{t}^{c} \equiv R_{t}^{f}$. Note that we implicitly assumed that firms do not default on their debt.

\subsection{Capital Owners}

Capital owners, of mass $\eta$, represent the top decile of income distribution. Similarly to workers, they maximize a discounted sum of utility over consumption, $c_{t}^{c}$,

$$
\max _{c^{c}, a^{c, c}, a^{s}} E_{0} \sum_{t=0}^{\infty} \beta_{t}^{c} \frac{\left(c_{t}^{c}\right)^{1-\gamma_{t}^{c}}}{1-\gamma_{t}^{c}},
$$

\footnotetext{
${ }^{8}$ In contrast, they are assumed to have full access to risk-free saving vehicules such as bank deposits $\left(a_{t}^{f}\right)$ and corporate bonds $\left(a_{t}^{c}\right)$. It is possible to assume $a_{t}^{c} \equiv 0$ without undermining the results of the paper.
} 
where $\beta_{t}^{c}$ is the capital owners' discount factor and $\gamma_{t}^{c}$ is their coefficient of risk aversion. The capital owners' coefficient of risk aversion is time-varying, as in Greenwald et al. (2016). In combination with technology shocks, which are the standard source of macroeconomic risk in our economy, shocks to the coefficient of risk aversion increase the price for risk that is, the return on the risky asset, net of risk-free return, per unit of risk, as traditionally measured by the excess return's standard deviation. In other words, they increase the Sharpe ratio.

The time-varying coefficient of risk aversion is defined as

$$
\gamma_{t}^{c}=\frac{\gamma^{c}}{1+\exp \left(x_{t-1}\right)}
$$

with $\gamma^{c}$ being the maximum degree of risk aversion and $x_{t}$ an autoregressive process of order 1 with mean $\mu^{x}: x_{t}-\mu^{x}=\rho^{x}\left(x_{t-1}-\mu^{x}\right)+\varepsilon_{t}^{x}$ and $\varepsilon_{t}^{x}$ an iid shock.

The maximization is subject to a budget constraint:

$$
c_{t}^{c}+a_{t}^{s} P_{t}^{s}+a_{t}^{c, c} P_{t}^{c}=W_{t}^{c} n_{t}^{c}+a_{t-1}^{s}\left(P_{t}^{s}+d_{t}^{s}\right)+a_{t-1}^{c, c},
$$

with $W_{t}^{c}$ the wage rate received by capital owners, $a_{t}^{s}$ and $a_{t}^{c, c}$ the number of stocks and corporate bonds held by capital owners, respectively, $P_{t}^{s}$ the stock price and $d_{t}^{s}$ the (economic) dividend received by capital owners from holding stocks. $n_{t}^{c}=n^{c}$ is their constant supply of labor.

Assuming the usual transversality condition, first order conditions for the capitalist's problem are:

$$
\begin{gathered}
\left(c_{t}^{c}\right)^{-\gamma_{t}^{c}}=\lambda_{t}^{c} \\
1=\beta_{t}^{c} E_{t} \frac{\lambda_{t+1}^{c}}{\lambda_{t}^{c}} R_{t+1}^{s} \\
1=\beta_{t}^{c} E_{t} \frac{\lambda_{t+1}^{c}}{\lambda_{t}^{c}} R_{t}^{c}
\end{gathered}
$$

with $\lambda_{t}^{c}$ the marginal utility of consumption and $R_{t+1}^{s}$ is the next period return on stocks:

$$
R_{t+1}^{s}=\frac{P_{t+1}^{s}+d_{t+1}^{s}}{P_{t}^{s}}
$$

The form of the above first order conditions is very similar to the standard first order conditions dirived in the CCAPM literature. However, since risk-free assets are now held by two types of agents, whose consumption is allowed to display different dynamics, Euler equations of capital owners and workers associated with these assets 
are, in most general case, inconsistent with each other. To deal with this problem, we apply the definition of time-varying discount factors as in Greenewald et al. (2016):

$$
\begin{aligned}
& \beta_{t}^{c} \equiv \beta\left[E_{t} \frac{\lambda_{t+1}^{c}}{\lambda_{t}^{c}}\right]^{-1} \\
& \beta_{t}^{w} \equiv \beta\left[E_{t} \frac{\lambda_{t+1}^{w}}{\lambda_{t}^{w}}\right]^{-1}
\end{aligned}
$$

where $0<\beta<1$. These definitions guarantee consistency of both sets of Euler equations, while at the same time deal with the problem of too volatile risk-free rate, see Greenewald et al (2016), making the risk-free rate in the economy constant: ${ }^{9}$

$$
R_{t}^{c} \equiv R_{t}^{c} \equiv \frac{1}{\beta}
$$

\subsection{Firms}

Identical competitive firms, of mass 1 , maximize the present value of their future profits, $D_{t}$, discounted at the marginal rate of substitution, $\beta^{t} \frac{\lambda_{t+1}^{c}}{\lambda_{0}^{c}}$, of the firms' owners:

$$
\max _{K, N^{c}, N^{w}} \sum_{t=0}^{\infty} \beta^{t} E_{t} \frac{\lambda_{t+1}^{c}}{\lambda_{0}^{c}} D_{t}\left(K_{t-1}, K_{t}, N_{t}^{c}, N_{t}^{w}\right)
$$

where $K_{t}$ is the end of period capital stock and $N_{t}^{c}$ and $N_{t}^{w}$ indicate demand for the capital owners' and workers' labor, respectively. Profits are defined as:

$$
D_{t}\left(K_{t-1}, K_{t}, N_{t}^{c}, N_{t}^{w}\right) \equiv D_{t}=Y_{t}-W_{t}^{c} N_{t}^{c}-W_{t}^{w} N_{t}^{w}-I_{t}+P_{t}^{b} \mu K_{t}-\mu K_{t-1}
$$

Above, $Y_{t}$ is the current output, $I_{t}$ is total investment and $\mu$ measures the degree of financial leverage of firms. When $\mu=0$, the new capital of a firm is fully financed through retained earnings. It will be assumed that profits are redistributed via dividends to capital owners: $d_{t}^{s}=D_{t} \cdot{ }^{10}$

Output is produced with Cobb-Douglas technology:

$$
Y_{t}=A K_{t-1}^{\theta}\left(\exp \left(z_{t}\right)\left(N_{t}^{c}\right)^{\alpha}\left(N_{t}^{w}\right)^{1-\alpha}\right)^{1-\theta}
$$

\footnotetext{
${ }^{9}$ Another well-established solution to the volatility puzzle is disentangling the risk aversion and intertemporal elasticity of substitution coefficients, which are the reciprocals of each other in our model, by using the Epstein-Zin-Weil utility function (Epstein and Zin, 1989 and 1991; Weil, 1990). While this would solve the risk-free rate volatility problem, it would not, on its own, assure consistency between the arbitrage conditions.

${ }^{10}$ Note that, as is common in the literature, e.g. Lansing (2015), we use the concept of "macroeconomic dividends" in place of financial dividends.
} 
where $\theta$ is the capital income share, $\alpha(1-\theta)$ is the capital owners' share of labor income and $z_{t}=z_{t-1}+\mu^{z}+\varepsilon_{t}^{z}$ is a TFP shock with possibly non-zero growth rate, $\mu^{z}$, and $\varepsilon_{t}^{z}$ is zero-mean N.I.D.

It is assumed that transforming investment $I_{t}$ into capital $K_{t}$ is costly, which permits the shadow price of installed capital to diverge from the price of an additional unit of capital. In specifying the capital adjustment cost, we follow Uhlig (2007) and Jermann and Quadrini (2012) so that the capital accumulation equation takes the form:

$$
K_{t}=(1-\delta) K_{t-1}+G\left(\frac{I_{t}}{K_{t-1}}\right) K_{t-1}
$$

with function $G(\bullet)$ such that

$$
G\left(\frac{I_{t}}{K_{t-1}}\right)=\frac{a_{1}}{1-\frac{1}{\xi}}\left(\frac{I_{t}}{K_{t-1}}\right)^{1-\frac{1}{\xi}}+a_{2}
$$

where $a_{1}, a_{2}$ are two positive constants. For $\xi<\infty$, adjustment costs become strictly positive.

Assuming transversality condition, first order conditions are as follows:

$$
\begin{gathered}
W_{t}^{w}=(1-\theta)(1-\alpha) \frac{Y_{t}}{N_{t}^{w}} \\
W_{t}^{c}=(1-\theta) \alpha \frac{Y_{t}}{N_{t}^{c}} \\
1=\beta_{t}^{c} E_{t} \frac{\lambda_{t+1}^{c}}{\lambda_{t}^{c}} R_{t+1}^{k}
\end{gathered}
$$

where return on capital, $R_{t}^{k}$, is defined as:

$$
R_{t+1}^{k}=\frac{G^{\prime}\left(\frac{I_{t}}{K_{t-1}}\right)}{1-G^{\prime}\left(\frac{I_{t}}{K_{t-1}}\right) \mu P_{t}^{b}}\left(\theta \frac{Y_{t+1}}{K_{t}}-\mu+\frac{1-\delta+G\left(\frac{I_{t+1}}{K_{t}}\right)}{G^{\prime}\left(\frac{I_{t+1}}{K_{t}}\right)}-\frac{I_{t+1}}{K_{t}}\right)
$$

which can also be rewritten as

$$
R_{t+1}^{k}=\frac{D_{t+1}+\frac{\left(1-G^{\prime}\left(\frac{I_{t+1}}{K_{t}}\right) \mu P_{t+1}^{b}\right)}{G^{\prime}\left(\frac{I_{t+1}}{K_{t}}\right)} K_{t+1}}{\frac{\left(1-G^{\prime}\left(\frac{I_{t}}{K_{t-1}}\right) \mu P_{t}^{b}\right)}{G^{\prime}\left(\frac{I_{t}}{K_{t-1}}\right)} K_{t}}
$$

The return on capital has an intuitive interpretation, which will be presented below. 


\subsection{Equilibrium market clearing conditions}

In the equilibrium, all markets clear:

- Consumption goods market: $C_{t}^{w}=(1-\eta) c_{t}^{w}, C_{t}^{c}=\eta c_{t}^{c}$ and $C_{t}^{w}+C_{t}^{c}=C_{t}$

- Goods market: $C_{t}+I_{t}=Y_{t}$

- Labor market: $N^{w}=(1-\eta) n^{w}, N^{c}=\eta n^{c}$ and $N^{w}+N^{c}=N$

- Asset markets: $a_{t}^{s}=\eta^{-1}, a_{t}^{f}=0, B_{t}^{c, w}=(1-\eta) a_{t}^{w}, B_{t}^{c, c}=\eta a_{t}^{c}$ and $B_{t}^{c, w}+$ $B_{t}^{c, c}=\mu K_{t}$

In the above, large-case-letters refer to aggregate (per capita) variables. Since, the share of corporate bonds held by capital owners (and workers) is not pinned down by the Euler equations, we make an additional assumption that $B_{t}^{c, w} \equiv \mu K_{t}$ or, alternatively, $B_{t}^{c, c} \equiv 0$. Any alternative assumption, including $B_{t}^{c, w} \equiv 0$ and $B_{t}^{c, c} \equiv \mu K_{t}$, produces results similar to those reported in the paper.

The whole list of equations, after having been stationarized (divided by $\exp \left(z_{t-1}\right)$ ) is shown in Appendix A).

\subsection{Asset Pricing Variables}

We define the equity premium (excess return on stocks):

$$
R_{t+1}^{e}=R_{t+1}^{s}-R_{t}^{f}
$$

The unconditional Sharpe ratio is then defined as:

$$
S R=\frac{E\left[R_{t}^{e}\right]}{\sigma\left[R_{t}^{e}\right]}
$$

where $E$ and $\sigma$ stand for unconditional expectation and standard deviation, respectively. For the sake of completeness, we also define price-dividend ratio $p d_{t}$, the standard stock market diagnostic:

$$
p d_{t}=\frac{P_{t}^{s}}{d_{t}^{s}}
$$

Finally, it is worth interpreting the Euler equation associated with capital. Comparing arbitrage conditions (8) and (15), we see that they imply

$$
P_{t}^{s}=\frac{\left(1-G^{\prime}\left(\frac{I_{t}}{K_{t-1}}\right) \mu P_{t}^{b}\right)}{G^{\prime}\left(\frac{I_{t}}{K_{t-1}}\right)} K_{t}
$$


In a model without frictions, stock price, $P_{t}^{s}$, would be simply equal to capital stock per capita, $K_{t}$. However, in our model, the price of installed and uninstalled capital differ. The adjustment term $G^{\prime}\left(\frac{I_{t}}{K_{t-1}}\right)$ translates the value of installed capital into the uninstalled one. Moreover, stock owners own only a fraction $1-\mu$ of capital stock, as they have to borrow from workers the funds to cover the remaining part of capital.

This is reflected in the $\left(1-G^{\prime}\left(\frac{I_{t}}{K_{t-1}}\right) \mu P_{t}^{b}\right)$ adjustment term (again, with a suitable adjustment due to the price difference between installed and unistalled capital).

\subsection{Intuition of the model}

\subsubsection{Mechanisms generating high equity premium and Sharpe ratio}

Our model is able to easily generate realistic equity premium and Sharpe ratio, and produce at the same time reasonable real-economy statistics. This is remarkable, given the well-known fact that production-based CCAPMs struggle to achieve both objectives at the same time (e.g. Lansing 2015, Guvenen 2009). Several elements of the model contribute to its success.

The source of macroeconomic risk in the model is a technology shock. To generate a high price for risk, following Greenwald et al. (2016), we introduce high and timevarying coefficient of risk-aversion in capital owners' utility function. In a standard 1-type of agents model, high and time-varying risk aversion would, via the Euler equation on capital, have a very strong impact on the real side of the economy. However, with two types of agents and a relatively small number of capital owners relative to the total number of consumers, the total consumption is not very strongly affected by shocks to risk aversion. This helps us generate real economy statistics that are similar to those in a baseline RBC model and reasonably close to their real-life counterparts.

While high and volatile coefficient of risk aversion of capital owners makes it possible to produce almost arbitrarily high equity premium, it is not sufficient on its own to generate a realistic Sharpe ratio. Production-based CCAPMs tend to produce too small the quantity of risk, as measured by the unconditional standard deviation of excess returns. We introduce two mechanisms to deal with this problem. First, we assume that capital is subject to adjustment costs. This mechanism makes capital owners' consumption smoothing via adjustment in the level of corporate investment costlier, making them less keen on taking investment risks. Additionally, capital adjustment costs help us match the volatility of investment relative to output. Second, we also introduce a limited amount of financial leverage of firms in the form of risk- 
free corporate debt. This multiplies the risk taken up by capital owners per each stock held.

\subsubsection{Expected responses of equity premium to shifts in income shares}

The objective of the paper is to examine the impact of shifts in income shares on the stock market variables and in particular on the equity premium. Using the model, we can make the following predictions. An increase in the capital income ratio, as governed by the production function parameter $\theta$, will lead to an increase in the mean equity premium. The reason is that higher $\theta$ directly increases the volatility of return on capital, via (16), which raises the riskiness of investment in stocks and hence increases the required excess return on stocks.

A shift in the labor income share of capital owners in total income, $\tilde{\alpha}=\alpha(1-\theta)$, has a less direct effect. Combining the capital owners' budget constraint (7) with the definition of dividends (10), we can write capital owners' consumption as:

$$
c_{t}^{c}=\tilde{\alpha} \frac{Y_{t}}{\eta}+\frac{D_{t}}{\eta} .
$$

The first term on the RHS of (18) represents the total labour income of capital owners. This is a part of capital owners' income that is relatively less risky. The second term is simply capital income, equal to total dividends income. This is the relatively more risky part of their income. From the above, it is clear that an upward shift in $\tilde{\alpha}$ will decrease consumption risk faced by capital owners, by increasing the weight of the less risky component of capital owners' income. As a result, the volatility of the associated stochastic discount factor, $M_{t}^{c}=\beta_{t}^{c} \frac{\lambda_{t+1}^{c}}{\lambda_{t}^{c}}$, and the mean stock excess return will fall.

From the above reasoning, using definition $\tilde{\alpha}=\alpha(1-\theta)$, it is also clear that an increase in the capital share of income, $\theta$, will have an additional indirect effect on the mean equity premium, by raising the relative weight of the riskier component in capital owners' consumption. This effect reinforces the direct effect of a shift in $\theta$ discussed earlier. Since we observe an increase in both shares of incomes in the data, we use a set of simulations of the model calibrated to the US economy to quantify the net effect of these two simultaneous shifts. ${ }^{11}$

\footnotetext{
${ }^{11}$ An additional trend that could have been observed through the last decades was a steady increase in stock ownership among households. A seminal result in the literature is that limited stock market participation helps explain high excess returns observed on stock markets (Vissing-Jorgensen, 2002). By this token, the steady increase of stock ownership should have contributed to the falling equity premium. Our model, in its baseline version presented above, is not able to capture this insight.
} 


\subsection{Computation}

For solving the model, we use a non-linear solution method based on Coleman and Fenyes (1992) and following Davig (2004) and Lendvai and Raciborski (2014). ${ }^{12}$ The details of this procedure are described in Appendix A. In order to compute the statistical moments of macro and financial variables, for every model parametrization of interest we simulate the economy for 1.020.000. The moments reported are based on time series consisting of the last 1.000 .000 observations. ${ }^{13}$

\subsection{Calibration}

Our calibration strategy is as follows. We calibrate most real economy parameters to reflect certain empirical properties of the economy in the post-war period, see Table 2. Parameter $\beta$ is calibrated to match the mean annual risk-free rate $E\left(R_{t}^{f}\right)=2 \%$. The share $\eta$ of capital owners in the population is equal to the top income decile. The remaining three real economy parameters (capital income share, $\theta$, capital owners' labor income share in total labor income, $\alpha$, and the ratio of capital owners to workers employment) are calibrated so that to match certain economy-wide characteristics in 1970 (see Table 2). Finally, the financial leverage parameter $(\mu)$ and risk aversion shock parameters $\left(\gamma^{c}, \mu^{x}, \rho^{x}, \sigma^{x}\right)$ are chosen to match a set of stock market statistics and are reported in Table 3 .

Starting from the real economy statistics, the value of $\sigma^{z}$, is chosen such that the volatility of output growth in our economy matches its empirical counterpart of $2 \%$ annually. The value of capital adjustment cost parameter, $\xi$, is chosen to come close to the ratio of volatility of investment growth to volatility of output growth equal to 2.84. The remaining parameters in the capital adjustment cost function are specified so that the steady state investment to capital ratio equals the depreciation rate and the first derivative of this function in investment-capital ratio is equal to 1 , as in Uhlig (2007) and Jermann and Quadrini (2012). The value of depreciation rate, $\delta$, is set to $8 \%$, annually.

The following parameter values are set to their 1970 empirical counterparts. The capital share of income was $35 \%$ in 1970 . Because the top $10 \%$ the richest owns approximately $80 \%$ of the total capital stock in the U.S. economy, we compute their share as $0.8 \times 0.35=0.28$ and set $\theta_{1970}=0.28$ in 1970 . Similarly the value of $\theta_{2014}$ is

\footnotetext{
${ }^{12}$ Our codes are based on sample codes for the solution of a bare-bone RBC model provided by Troy Davig.

${ }^{13}$ The first 20000 observations are burn-in.
} 
Table 2: Calibration of the main parameter values

\begin{tabular}{ccl}
\hline & \multicolumn{1}{c}{ Table 2: Baseline Parameter Values } \\
\hline \hline Parameter & Value & \multicolumn{1}{c}{ Description/Target } \\
\hline$\eta$ & 0.10 & Capital owners = top income decile. \\
$\theta_{1970}$ & 0.28 & Capital's share of income of top 10\% in 1970: $0.8 \times 35 \%=0.28$ \\
$\alpha_{1970}$ & 0.05 & Top decile income share $=3.5 \%$ in 1970. \\
$N_{1970}^{c} / N_{1970}^{w}$ & 0.19 & Mean relative wage $W_{0}^{c} / W_{0}^{w}=2$ in 1970. \\
$\mu^{z}$ & 0.00 & \\
$\sigma^{z}$ & $7.7160 e^{-4}$ & Output volatility of $2 \%$ in the post-war period. \\
$\rho^{z}$ & 0 & $R W$ \\
$\delta$ & 0.08 & Annual depreciation rate of $8 \%$ \\
$\xi$ & 0.33 & Ratio of volatility of investment to volatility of output $\frac{\sigma^{\Delta I}}{\sigma^{\Delta y}} \simeq 2.84$. \\
$a_{1}$ & $2.2000 e^{-4}$ & Steady state investment to capital ratio equal to depreciation rate. \\
$a_{2}$ & 0.11 & $G^{\prime}\left(\frac{I_{t}}{K_{t-1}}\right)=1$ \\
$\beta$ & 0.98 & $R_{t}^{f}=1.02$ \\
\hline
\end{tabular}

computed by multiplying total capital share of income by 0.8 . The value of parameter $\alpha_{1970}$ is set so that the top decile income share, $\alpha_{1970}\left(1-\theta_{1970}\right)=3.5 \%$. Further, without a loss of generality, we set the demand for capital owners' labor in the model equal to 1. Following Lansing (2015), we then choose the value of demand for workers' labor such that the relative wage of capital owners to workers, $W_{0}^{c} / W_{0}^{w}=2$, its value in 1970.

Table 3 reports baseline parameter values for stock market. The financial leverage, $\mu$, and maximum risk aversion parameter, $\gamma^{c}$, are calibrated to reproduce as closely as possible two fundamental stock market statistics, the mean equity premium, $E R_{t+1}^{e}=$ $7.03 \%$ and the Sharpe ratio, $S R=0.43$, in the post-war S\&P 500. We need a much lower maximum degree of capital owners' risk aversion than Greenwald et al. (2016), $\gamma^{c}=100$. This also translates into a much lower mean degree of capital owners' risk aversion, which in our baseline calibration is $E\left(\gamma_{t}^{c}\right)=26$. The main reason for this difference is the assumption of a moderate degree of financial leverage, absent in Greenwald et al. (2016). The value of financial leverage, $\mu=21 \%$, is close to the value of $15 \%$ assumed by Guvenen's (2009) and is conservative in comparison to values used in the literature (e.g. Boldrin et al., 2001, assume leverage of 50\%). The mean of the shock process to the coefficient of risk aversion $\mu^{x}=-1.1$ is set to match log price-dividend ratio and its variance, $\sigma^{x}=0.4$, to replicate the empirical dividends' growth volatility. Finally, we set the $\operatorname{AR}(1)$ coefficient of the risk aversion shock, $\rho^{x}$, 
Table 3: Baseline parameter values for stock market

\begin{tabular}{ll}
\hline Parameter & Value \\
\hline$\mu$ & 0.21 \\
$\gamma^{c}$ & 100 \\
$\min \left(\gamma_{t}^{c}\right)$ & 1 \\
$\mu^{x}$ & -1.1 \\
$\sigma^{x}$ & 0.4 \\
$\rho^{x}$ & 0.95 \\
\hline
\end{tabular}

\begin{abstract}
Table includes calibrated values of the coefficient of risk aversion, $\gamma_{t}^{c}$, and its $\operatorname{AR}(1)$ shock. Risk aversion coefficient is defined as: $\gamma_{t}^{c}=\frac{\gamma^{c}}{1+\exp \left(x_{t}\right)}$ with $\gamma^{c}$ being maximum degree of risk aversion and $x_{t}$ an $\operatorname{AR}(1)$ process with mean $\mu^{x}: x_{t}-\mu^{x}=\rho^{x}\left(x_{t-1}-\mu^{x}\right)+\varepsilon_{t}^{x}$ and $\varepsilon_{t}^{x}$ an iid shock with variance $\left(\sigma^{x}\right)^{2}$.
\end{abstract}

to match the well documented long-horizon predictability of equity premium.

\title{
4 Quantitative Performance of the Model
}

We proceed as follows. We first simulate our model for the parameter calibration given in Tables 2 and 3, and in particular, for the capital share of income $\theta=0.28$ and the share of capital owners' labor income in total labor income $\alpha=0.05$. We assess its performance by comparing a set of model-based statistics with the data.

In order to study the impact of changes in income inequality on the equity premium, we then run 3 additional simulations. We first consider a rise in capital income inequality. We change the value of $\theta$ from its baseline value to 0.34 and study the impact of this increase on the mean equity premium. Second, we increase the value of $\alpha$ to $13 \%$, its 2014 value, and analyze the effect of this change. Finally, similar to the trends in the data, we consider the joint shifts in the capital and labour shares of income. To isolate the impact of income shares shifts on the equity premium, we keep all the other parameters of the model unchanged.

\subsection{Baseline scenario}

We first discuss the performance of the baseline version of the model calibrated to the post-war U.S. real economy and S\&P 500 index. In the top panel of Table 4, we report stock market statistics and in the lower panel real economy statistics. Both 
panels include the moments observed in the U.S. data and in the model. All the asset pricing statistics are based on the annual S\&P 500 series coming from Robert Shiller's website and covering post-war period between 1947 and 2014. The real economy statistics are based on the series computed by U.S. Bureau of Economic Analysis and retrieved from the FRED at St Louis Fed.

The first two rows of Table 4 report the average equity premium and Sharpe ratio. Our baseline model specification reproduces the historical equity premium on the U.S. stock market and produces sizeable Sharpe ratio. The third and fourth rows of the same table display $\log$ price-dividend ratio, $\ln \left(\frac{P_{t}^{s}}{D_{t}}\right)$. While the model is able to match the volatility of the ratio, $\sigma^{\ln \left(\frac{P}{D}\right)}$, it somewhat underpredicts its log-level. Finally, the volatility of dividend growth of $7 \%$ is well matched by the model.

On the real side of the economy, the model replicates the volatility of output growth, $\sigma^{\Delta y}$ and comes close to matching the investment-output volatility ratio, $\frac{\sigma^{\Delta I}}{\sigma^{\Delta y}}$. The model slightly overpredicts the consumption-output volatility ratio, $\frac{\sigma^{\Delta c}}{\sigma^{\Delta y}}$. The reason is that, in the model, relatively high volatility of capital owners' consumption is required to match the high equity premium and Sharpe ratio observed in the data. Since workers consume less on average, capital owners' consumption constitutes an important part of total consumption, despite the much lower number of them in the total population, so that total consumption volatility is strongly affected by the volatility of capital owners' consumption.

In addition to the unconditional moments we compute the long-horizon predictability of equity premium based on the price-dividend ratio. We estimate a specification of the following form:

$$
\sum_{j=0}^{h} R_{t+j+1}^{e}=\beta \frac{P_{t}^{s}}{D_{t}}+\varepsilon_{t+1, t+h}
$$

where $\sum_{j=0}^{h} R_{t+j+1}^{e}$ is a cumulative excess return over $h+1$ years with $h=0,1,2, \frac{P_{t}^{s}}{D_{t}}$ is price-dividend ratio at time $t$, and $\varepsilon_{t+1, t+h}$ is the error term. The results of the estimation of this specification for S\&P 500 series are reported in the top panel of Table 5 while their model-based counterparts are displayed in the lower panel of the same table. We find that a drop in current price-dividend ratio predicts increase in the future cumulative excess returns both in the data and in the model. The absolute value of estimated coefficient $\beta$ as well as $R^{2}$ increase in the horizon $h$. 


\section{Table 4: Unconditional asset pricing and real economy moments in the model and the U.S. data}

\begin{tabular}{llcl}
\hline Variable & \multicolumn{1}{c}{ Moment } & Data & Model \\
\hline \hline \multicolumn{4}{c}{ Stock market } \\
\hline$R_{t+1}^{e}$ & Equity premium & 7.03 & 7.04 \\
$\frac{E\left[R_{t}^{e}\right]}{\sigma\left[R_{t}^{e}\right]}$ & Sharpe ratio & 0.43 & 0.38 \\
$\ln \left(\frac{P_{t}^{s}}{D_{t}}\right)$ & Log Price-Dividend ratio & 3.41 & 2.71 \\
$\sigma^{\ln \left(\frac{P}{D}\right)}$ & Volatility of Log Price-Dividend ratio & 0.45 & 0.59 \\
$\sigma^{\Delta D}$ & Volatility of dividend growth & 0.07 & 0.07 \\
\hline \multicolumn{4}{c}{ Real economy } \\
\hline$\sigma^{\Delta y}$ & Volatility of Output Growth & $2 \%$ & $2 \%$ \\
$\frac{\sigma^{\Delta I}}{\sigma^{\Delta y}}$ & Ratio vol investment growth-vol output growth & 2.84 & 2.10 \\
$\frac{\sigma^{\Delta c}}{\sigma^{\Delta y}}$ & Ratio vol consumption growth-vol output growth & 0.76 & 1.15 \\
\hline \multicolumn{2}{c}{}
\end{tabular}

Equity premium, Sharpe ratio and price-dividend ratio are computed using the annual data from Shiller's website: http://www.econ.yale.edu/ shiller/data.htm. Equity premium is computed as the difference between the return including dividends on S\&P 500 and the risk free rate. Risk free rate is 6 months rolled commercial paper rate. Price-dividend ratio is calculated for S\&P 500. Volatility is measured by standard deviation. $\Delta x$ stands for growth rate in variable $x$. The real economy data is from FRED. Real output is proxied by real GDP, real investment by private non-residential fixed investment and consumption by real personal consumption expenditures. All the real economy variables are originally expressed in Billions of Chained 2009 Dollars and we compute their annual growth rates. 
Table 5: Long Run Return Predictability Regressions

\begin{tabular}{|c|c|c|}
\hline \multirow[t]{2}{*}{ Long Horizon Return Regressions } & \multicolumn{2}{|c|}{$\sum_{j=0}^{h} R_{t+j+1}^{e}=\beta \frac{P_{t}^{s}}{D_{t}}+\varepsilon_{t+1, t+h}$} \\
\hline & \multicolumn{2}{|c|}{ Data } \\
\hline$X_{t}:$ & $\frac{P_{t}^{s}}{D_{t}}$ & $R^{2}$ \\
\hline$h$ & & \\
\hline 0 & $\begin{array}{c}-0.23^{* *} \\
(0.11)\end{array}$ & 0.05 \\
\hline 1 & $\begin{array}{c}-0.48^{* *} \\
(0.18)\end{array}$ & 0.11 \\
\hline \multirow[t]{2}{*}{2} & $\begin{array}{c}-0.67^{* *} \\
(0.22)\end{array}$ & 0.16 \\
\hline & \multicolumn{2}{|c|}{ Model } \\
\hline$h$ & & \\
\hline 0 & $\begin{array}{c}-0.21^{* * *} \\
(0.002)\end{array}$ & 0.01 \\
\hline 1 & $\begin{array}{c}-0.41^{* * *} \\
(0.002)\end{array}$ & 0.02 \\
\hline 2 & $\begin{array}{c}-0.58^{* * *} \\
(0.003)\end{array}$ & 0.03 \\
\hline
\end{tabular}

Table reports results of estimation of the regression $\sum_{j=0}^{h} R_{t+j+1}^{e}=\beta \frac{P_{t}^{s}}{D_{t}}+\varepsilon_{t+1, t+h}$ where $\sum_{j=0}^{h} R_{t+j+1}^{e}$ is a cumulative excess return over $\mathrm{h}+1$ years with $\mathrm{h}=0,1,2 . \frac{P_{t}^{s}}{D_{t}}$ is price-dividend ratio at time $t$ and $\varepsilon_{t+1, t+h}$ is the error term. The specification is estimated by OLS with Newey-West correction of the standard errors. Standard errors are reported in brackets. 


\section{Increase in Income Inequality and Equity Premium}

How did the trends in inequality affect stock market and, in particular, equity premium? Between 1970 and 2014 the capital income share of top decile increased by 6 percentage points (from $28 \%$ to $34 \%$ of total U.S. income), while the top decile labor income share increased by about 9.5 percentage points (from $3.5 \%$ to $13 \%$ of total U.S. income). In order to gauge the impact of these shifts on equity premium, we simulate the model economy with higher income inequality observed in 2014. Specifically, we set the income share parameters to their 2014 steady state values.

Table 6: Income shares shifts and mean equity premium

\begin{tabular}{cccc}
\hline Scenario & Parameter values & Equity premium & Change vs baseline \\
\hline Baseline & $\theta=0.28 ; \alpha=0.05$ & $7.04 \%$ & - \\
$\theta \Uparrow$ & $\theta=0.34 ; \alpha=0.05$ & $7.43 \%$ & $+0.43 p p$ \\
$\alpha \Uparrow$ & $\theta=0.28 ; \alpha=0.20$ & $5.76 \%$ & $-1.64 p p$ \\
$\theta$ and $\alpha \Uparrow$ & $\theta=0.34 ; \alpha=0.20$ & $6.25 \%$ & $-0.79 p p$ \\
\hline
\end{tabular}

$\theta \Uparrow$ denotes an increase in capital share of income and $\alpha \Uparrow$ an increase in the labour share of income of capital owners. The equity premium in the model is computed over 1.000.000 simulated periods. All the parameters of the model except for the ones included in the table are set to their baseline calibration values reported in Tables 2 and 3 .

As explained earlier (section 3.6.2), we expect shifts in the capital income and top decile labor income shares to have opposite effects on equity premium. In order to test numerically this intuition, we first examine each income shift separately. First, we keep $\alpha$ at its 1970 value but increase $\theta$ to match the 2014 value of the capital income share. Next, we do the opposite: we keep $\theta$ at its 1970 value, but increase $\alpha$ to its 2014 level. Finally, to assess the total, quantitative impact of the simultaneous trends in income shares observed in the data, we introduce both shifts together. The results of these exercises are reported in Table 6 .

The first row shows the baseline model simulation outcomes where the equity premium equals $7.04 \%$ and the second row displays the results of the simulation with a higher capital income inequality as measured by increased $\theta$. Increase in the share of income derived from the risky source, requires a higher return on the risky asset and translates into a higher equity premium. An increase in the capital share of income of 6 percentage points generates an increase in equity premium of 0.43 percentage points. 
The third row reports the results of the counterfactual with $\theta$ kept unchanged at its 1970 value, and $\alpha$ set to its 2014 level. A 15 percentage points increase in $\alpha$ translates into a large drop in equity premium of 1.64 percentage points. Unsurprisingly, considered simultaneously the shifts generate a drop in equity premium. An economy with higher shares of income, as observed in the U.S. data, displays equity premium of $6.25 \%$. The reason is that, during the last five decades the capital owners benefited from a higher average growth in their non-risky labour income share relative to the risky capital income share ( $2 \%$ versus $0.5 \%$ on per year).

In addition to the equity premium, we look at the impact of changes in income shares on other asset pricing variables. Table 7 shows the figures for Sharpe ratio, log price-dividend ratio, volatility of log-price-dividend ratio and volatility of dividend growth.

Table 7: Asset pricing moments in different scenarios

\begin{tabular}{cccccc}
\hline Scenario & Parameter values & SR & $\log \mathrm{P} / \mathrm{D}$ & sd $\log \mathrm{P} / \mathrm{D}$ & sd. div. gr. \\
\hline Baseline & $\theta=0.28 ; \alpha=0.05$ & 0.38 & 2.71 & 0.59 & 0.07 \\
$\theta \Uparrow$ & $\theta=0.34 ; \alpha=0.05$ & 0.38 & 2.71 & 0.62 & 0.07 \\
$\alpha \Uparrow$ & $\theta=0.28 ; \alpha=0.20$ & 0.35 & 2.81 & 0.56 & 0.07 \\
$\theta$ and $\alpha \Uparrow$ & $\theta=0.34 ; \alpha=0.20$ & 0.35 & 2.80 & 0.59 & 0.07 \\
\hline
\end{tabular}

$\theta \Uparrow$ denotes an increase in capital share of income and $\alpha \Uparrow$, an increase in the labour share of income of capital owners. The equity premium in the model is computed over 1.000.000 simulated periods. All the perimeters of the model except for the indicated ones are set to the baseline calibration values reported in Tables 2 and 3.

The second row shows the statistics under counterfactual with only $\theta$ shifting by 6 percentage points. We see that there is no impact on Sharpe ratio because increase in capital share of income raises both the return and the volatility of return on capital. Because changes in labour income share of capital owners have an impact only on the stock return, we find that an increase in $\alpha$ generates a drop in Sharpe ratio.

\subsection{Alternative scenarios and predictions}

How will the equity premium change by 2030 if the U.S. income inequality continues to increase? While it may be futile to try to predict income inequality changes, it is still of interest to study the most likely scenarios. Recent research suggests that, at least to some extent, the current trends will persist. Schwabish and Topoleski (2013) argue that the historical pattern of rising earnings inequality will continue for the 
next two decades. Piketty (2014) makes a strong claim that the capital income share will continue to grow as well. In line with these predictions, we extrapolate current inequality trends into the future, until 2030. Specifically, we assume that capital share of income, $\theta$, continues growing at a yearly $0.5 \%$, as observed between 1970 and 2014, on average. We also assume that the total top decile income share, $(1-\theta) \alpha+\theta$, will grow at the same rate as on average between 1970 and 2014, namely $0.92 \%$ per year. We then compute the resulting labour share of income of top decile, $(1-\theta) \alpha$. These assumptions imply that labour share of income of top decile increases at $2 \%$ per year. Next, using our model, we calculate the resulting equity premia, for both of these trends continuing simultaneously (scenario 1) as well as for an alternative scenario in which only capital share of income, $\theta$, continues increasing in the future (scenario 2 ).

Figure 3: Top decile income shares in the U.S. data and predictions (scenario 1)

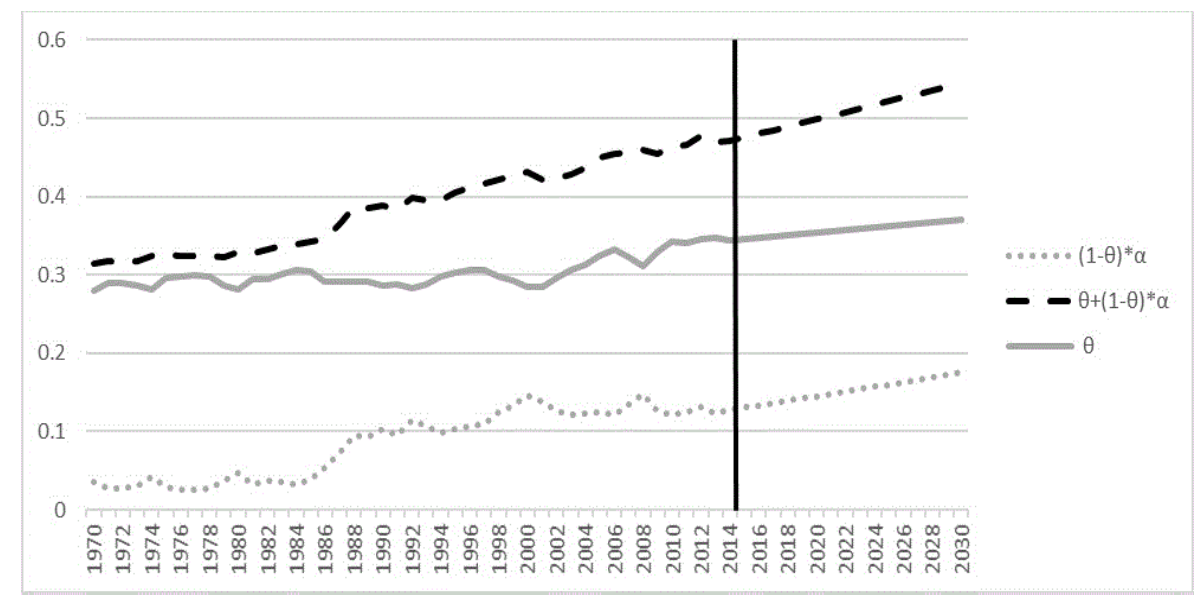

Dotted grey line plots the labour share of income of capital owners: $(1-\theta) \alpha$. Grey solid line plots capital share of income: $\theta$, and the dashed black line plots the sum of the two: $(1-\theta) \alpha+\theta$ which corresponds to top decile income share. The black vertical line indicates 2014 when the available data sample stops. Figures beyond 2014 correspond to the forecasted values. It is assumed that capital share of income, $\theta$, continues to grow at an annual $0.5 \%$ and the labour share of income of capital owners at an annual rate $2 \%$.

The evolution of the extrapolated income shares is plotted in Figure 3. The figure plots the labour share of income of capital owners: $(1-\theta) \alpha$ (grey dotted line), capital share of income: $\theta$ (grey solid line) and total share of income of top decile: $(1-\theta) \alpha+\theta$ (black dashed line). Beyond 2014, we plot linear forecasts in income share trends. If both labour and capital shares of income of top decile would continue growing at their trend rates until 2030, the capital share of income, $\theta$, would reach 
0.37, its labour share of income, $(1-\theta) \alpha, 0.18$, and the total top decile income share 0.55 . Note that if these trends would persist, top decile income share would double between 1970 and 2046 .

Table 8: Mean equity premium in different scenarios

\begin{tabular}{cccccccccc}
\hline & \multicolumn{1}{c}{ Average growth rates } & \multicolumn{3}{c}{ Parameter values } & EP & EP vs B1 & EP vs B2 \\
\hline \hline & $\Delta \theta$ & $\Delta(1-\theta) \alpha$ & $\theta$ & $\alpha$ & $(1-\theta) \alpha$ & $\theta+(1-\theta) \alpha$ & & & \\
\hline Baseline 1 & - & - & 0.28 & 0.05 & 0.04 & 0.32 & 7.04 & - & - \\
Baseline 2 & $0.5 \%$ & $2 \%$ & 0.34 & 0.20 & 0.13 & 0.47 & 6.25 & $-0.79 p p$ & - \\
Scenario 1 & $0.5 \%$ & $2 \%$ & 0.37 & 0.28 & 0.18 & 0.55 & 6.11 & $-0.92 p p$ & -0.14 \\
Scenario 2 & $0.5 \%$ & 0 & 0.37 & 0.20 & 0.13 & 0.49 & 7.61 & $+0.57 p p$ & +1.36 \\
\hline
\end{tabular}

$\Delta x$ stands for growth rate in variable $x . \theta$ is capital share of income. $(1-\theta) \alpha$ is labour share of income of top decile and $\theta+(1-\theta) \alpha$ is their total income share. EP stands for equity premium. EP vs B1 stands for equity premium versus baseline 1 and EP vs B2 versus baseline 2. Statistics are computed using model simulations of 1.000.000 periods. All the parameters except for the ones indicated in the table are set to the baseline calibration values reported in Table2.

Table 8 reports the parameter values and resulting equity premia in two "baseline" scenarios and two alternative scenarios based on income shares trends extrapolated in the future. The baseline scenarios assume that income shares parameters remain fixed in the future. The first baseline scenario (Baseline 1) corresponds to the initial calibration described in Table 2 where we match the stock market and real economy statistics in the post-war U.S. data. The second baseline scenario (Baseline 2) corresponds to the simulation with higher income inequality as observed in the data in 2014, and described in Tables 6 and 7. The last three columns of Table 8 report the mean equity premium, the difference relative to the first baseline and the difference relative to the second baseline scenario.

Unsurprisingly, under alternative Scenario 1 (both income share parameters continue increasing at the rates depicted in Figure 3), the equity premium would fall to $6.11 \%$ in 2030, 0.92 percentage point lower than the average post-war equity premium and 0.14 percentage point lower than in 2014. The mechanism driving this result is exactly the same as previously. An increasing share of risky assets in the portfolio of top decile requires higher return while a growing share of non-risky assets (labour income) implies lower return. Because the labour share of income grew faster than capital share of income between 1970 and 2014 (2\% versus $0.5 \%$ ), the growth in the labour income share dominates the one in the capital income share and generates 
a drop in equity premium.

We believe that the labour share of income of capital owners is unlikely to continue growing at its recent pace in the future. Until 2000s, the ICT (Information and Communication Technology) diffusion based skill-premium and resulting earnings dispersion was mainly driving the increase in income inequality. Grey dotted line in Figure 4 shows that the major increase in labour share of income of top decile occurred between 1980 and 2000. In contrast, capital share of income has been fairly stable until 2000s as shown in lower panel of Figure 1 but started to increase afterwards. In fact, Saez and Zucman (2016) show that an initial increase in the earnings of top incomes largely contributed to the accumulation of wealth and generated in turn an increase in capital income inequality. For this reason, in alternative Scenario 2 we assume that the labour share of income of capital owners remains constant from now and it is only the capital share of income that continues to increase until 2030. As in the first scenario, we compute the average yearly growth rate in the capital share of income between 1970 and 2014 and extrapolate it into the future. The labour share of income of top decile remains unchanged at 2014 value.

Figure 4: Top decile income shares in the U.S. data and predictions (scenario 2)

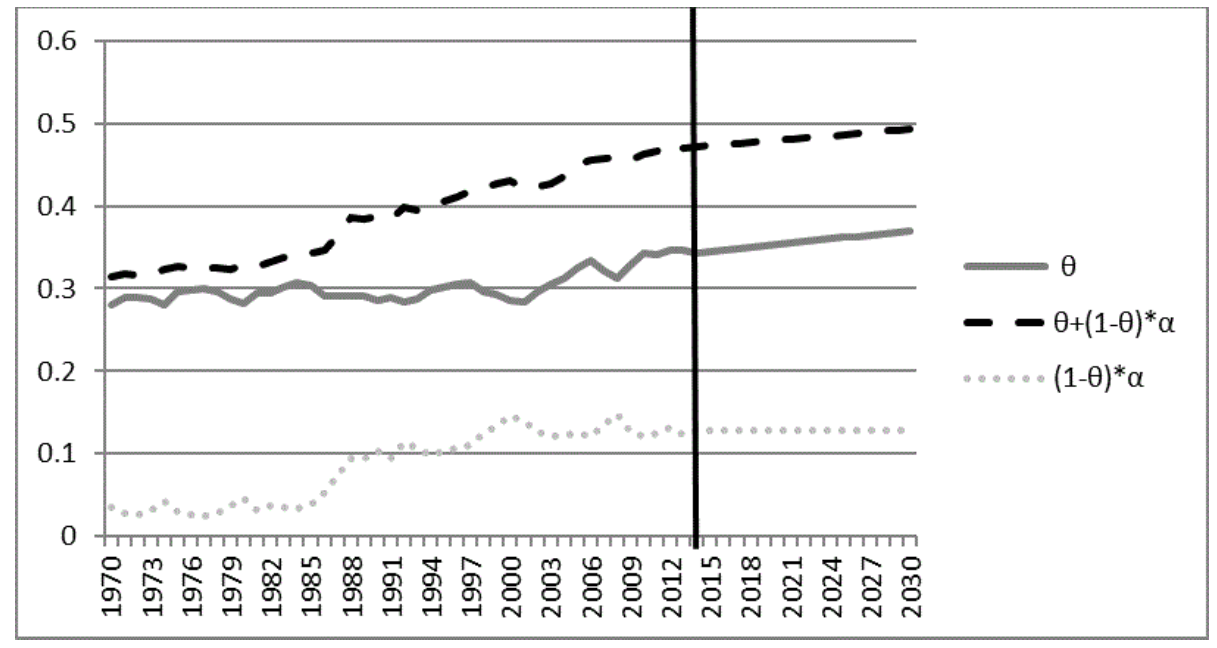

Dotted grey line plots the labour share of income of capital owners: $(1-\theta) \alpha$. Grey solid line plots capital share of income: $\theta$, and the dashed black line plots the sum of the two: $(1-\theta) \alpha+\theta$ which corresponds to top decile income share. The black vertical line indicates 2014 when the available data sample stops. Figures beyond 2014 correspond to the forecasted values. It is assumed that capital share of income, $\theta$, continues to grow at the annual $0.5 \%$ while the labour share of income of capital owners does not grow at all. 
Figure 4 shows the income inequality trends under this scenario. Again, beyond 2014 , we plot forecasted values of income shares. If capital share of income continues to grow at the annual rate of $0.5 \%$ and the labour share of income of top decile remains unchanged, capital share of income would reach $37 \%$ and total income share of capital owners would be equal to $49 \%$.

The last row of Table 8 reports the equity premium value under this scenario. Because we assumed that only capital share of income would keep on increasing, the equity premium would be higher than the historical (baseline 1) equity premium by 0.57 and higher by 1.36 relative to the equity premium between 1970 and 2014 .

\subsection{Counterfactual scenarios}

We are also interested in answering the following question: given the predicted trends in income shares, as extrapolated in the previous subsection, what changes in income inequality are required to bring the equity premium to its historical values? Here we assume that labour share of income remains at its 1970 level and we compute the level and implied growth of capital share of income, $\theta$, necessary to generate the average post-war equity premium of $7.03 \%$ (scenario 3 ). In scenario 4 , we repeat the exercise but this time we aim at the equity premium value in the period between 1947 and 1970, 9.07\% (first row of Table 9).

Table 9: Income inequality required to match historical equity premium

\begin{tabular}{lccccc}
\hline & Inputs into the model & Params to match EP & $\Delta$ to match EP & EP sample & EP \\
\hline Scenario 3 & $\alpha=0.20 ; \Delta \alpha=0$ & $\theta=0.430$ & $\Delta \theta=1.40 \%$ & $1947-2014$ & $7.03 \%$ \\
Scenario 4 & $\alpha=0.20 ; \Delta \alpha=0$ & $\theta=0.675$ & $\Delta \theta=4.31 \%$ & $1947-1970$ & $9.07 \%$ \\
\hline
\end{tabular}

$\Delta x$ stands for growth rate in variable $x . \theta$ is capital share of income. $(1-\theta) \alpha$ is labour share of income of top decile and $\theta+(1-\theta) \alpha$ is their total income share. ' $\Delta$ to match $\mathrm{EP}$ ' indicates the annual growth rate in one of the shares needed to match the EP. EP Statistics in the model are computed using model simulations of 1.000 .000 periods. All the parameters except for the ones indicated in the table are set to the baseline calibration values reported in Table 2. EP sample denotes the sample over which the equity premium in the data was computed.

The first row of Table 9 shows that if the labour income dispersion stops increasing, the historical equity premium of $7.03 \%$ would be reached by 2030 if capital share of income was growing by $1.4 \%$ each year, in line with Piketty's (2014) predictions. If the equity premium was instead, to reach its value from immediately after the war (scenario 4), the capital share of income would need to grow at the annual $4.31 \%$ 
until 2030, an unlikely scenario.

\section{Conclusion}

In this paper, we study the relationship between income inequality and stock market returns. We develop a general equilibrium model with capital owners who own $100 \%$ of the economy's financial wealth and workers who consume their labor income and income from risk-free government and corporate bonds. Motivated by recent empirical observation on the high correlation between capital and labour top incomes, capital owners in our model earn high labor income. Since capital owners are the ones who price the risky assets, changes in their both income sources affect the stock market variables.

In the model higher capital share of income increases the share of capital owners' consumption derived from risky source as well as the riskiness of investment. Both mechanisms generate higher equity premium. When the share of capital owners' income derived from the less risky source (labour) increases, the required risk premium drops and so does equity premium.

We calibrate the model to the post-war U.S. economy and simulate it with increased income inequality, as observed in 2014. We find that the impact of the labour share of income was quantitatively larger hence we observe a decrease in the equity premium consistent with the data.

We also use our set-up to carry out a number of counterfactual exercises. First we extrapolate current inequality trends into the future and, using the model, predict the potential equity premium. Second, we compute the level and growth in income inequality needed for the equity premium to go back to its historical mean of the post-war period.

If both capital and total income shares of top decile will grow until 2030 at the same rate as between 1970 and 2014, namely $0.5 \%$ and $0.92 \%$, respectively, the equity premium would continue decreasing to $6.11 \%$ in $2030,0.92$ percentage point lower than historical equity premium of $7.03 \%$. If capital share of income continues to grow at the annual rate of $0.5 \%$ and the labour share of income of top decile remains unchanged, the equity premium would be higher than the historical average by 0.57 percentage point.

If we assume that the labour income dispersion stops increasing, we find that the historical equity premium would be reached by 2030 if capital share of income was 
growing by $1.4 \%$ each year, consistent with Piketty's (2014) predictions. 


\section{References}

[1] Atkinson, A.B., T. Piketty, and Saez E. (2011) 'Top Incomes in the Long Run of History,' Journal of Economic Literature, 49(1), pp. 3-71.

[2] Boldrin, M., Christiano, L.J., and Fisher, J.D.M. (2001) 'Habit persistence, asset returns, and the business cycle' American Economic Review, 91(1), pp. 149-166.

[3] Chen, B., and Stafford, F.P. (2016) 'Stock Market Participation: Family Responses to Housing Consumption Commitments', Journal of Money Credit and Banking 48(1), pp. 635-659.

[4] Coleman, T., and Fenyes, P. (1992) 'Partitioned quasi Newton methods for nonlinear equality constrained optimization', Mathematical Programming 53, pp. $17-44$.

[5] Danthine, J.-P., and Donaldson, J.B. (2002) 'Labour Relations and Asset Returns, ' Review of Economic Studies, 69(1), pp. 41-64.

[6] Danthine, J.-P., and Donaldson, J.B. and Siconolfi, P. (2008) 'Distribution Risk and Equity Returns', in (R. Mehra, eds.), Handbook of the Equity Risk Premium, pp. 415-462, Amsterdam: Elsevier.

[27] Davig, T. (2004) 'Regime-switching debt and taxation', Journal of Monetary Economics, 51(4), pp. 837-859.

[7] Epstein, L., and Zin, S.(1989) 'Substitution, risk aversion, and the temporal behavior of consumption and asset returns: A theoretical framework.' Econometrica, 57, pp. 937-969.

[8] Epstein, L., and Zin, S. (1991) 'Substitution, risk aversion, and the temporal behavior of consumption and asset returns: An empirical analysis.' Journal of Political Economy, 99, pp. 263-286.

[9] Gottschalk, P., and Danziger, S. (2005) 'Inequality of Wage Rates, Earnings and Family Income in the United States, 1975-2002', Review of Income and Wealth, 51(2), pp. 231-254.

[10] Greenwald, D.L., Lettau, M. and Ludvigson, S.C. (2016) 'The Origins of Stock Market Fluctuations', NBER Working Paper No. 19818. 
[11] Guvenen, F., (2009) 'A Parsimonious Macroeconomic Model for Asset Pricing', Econometrica, 77(6), pp. 1711-1750.

[28] Guvenen, F., and Kuruscu, B. (2006) 'Does Market Incompleteness Matter for Asset Prices?', Journal of the European Economic Association, 4(2-3), pp. 484492.

[12] Heaton, J. and Lucas, D. (2000). 'Stock Prices and Fundamentals', in (B.S. Bernanke and J.J. Rotemberg, eds.), NBER Macroeconomics Annual 1999, pp. 213-264, Cambridge MA: MIT Press.

[13] Hurst, E., Luoh, M.C., and Stafford, F.P. (1998) 'The Wealth Dynamics of American Families, 1984-94', Brookings Papers on Economic Activity, 29(1), pp. 267-338.

[14] Jermann, U.J. (1998). 'Asset Pricing in Production Economies', Journal of Monetary Economics, 41, pp. 257-275.

[15] Jermann, U.J., and Quadrini, V. (2012) Macroeconomic eğects of Financial shocks. American Economic Review, 102, pp. 238-271.

[16] Kacperczyk, M., Nosal, J., and Stevens, L. (2016) 'Investor Sophistication and Capital Income Inequality', working paper.

[17] Karabarbounis, L., and Neiman, B. (2014) 'The Global Decline of the Labor Share', Quarterly Journal of Economics, 129(1), pp. 61-103.

[18] Lansing, K.J. (2015). 'Asset Pricing with Concentrated Ownership of Capital and Distribution Shocks', American Economic Journal-Macroeconomics, 7(4), pp. 67-103.

[19] Lansing, K.J., and Markiewicz, A. (2018). Top Incomes, Inequality and Welfare', Economic Journal, 128(608), pp. 262-297.

[20] Lendvai, J., and Raciborski, R. (2014) 'Pricing Financial Assets in an RBC Framework with Loss-Averse Agents', mimeo.

[21] Ludvigson (2009). 'Euler Equation Errors,' The Review of Economic Dynamics, 12(2), pp. 255-283. 
[22] Piketty, T. (2014). Capital in the Twenty-First Century, Cambridge, MA: Harvard University Press.

[23] Saez, E., and Zucman G. (2016) 'Wealth Inequality in the United States since 1913: Evidence from Capitalized Income Tax Data,' Quarterly Journal of Economics 131(2), pp. 519-578.

[24] Schwabish, J.A., and Topoleski, J. (2013) 'Modeling Individual Earnings in CBO's Long-Term Microsimulation Model', Working Papers 44306, Congressional Budget Office.

[25] Uhlig, H. (2007) 'Explaining Asset Prices with External Habits and Wage Rigidities in a DSGE Model,' American Economic Review P\&P, 97(2), pp. 239-243.

[26] Vissing-Jorgensen, A. (2002) 'Limited Asset Market Participation and Intertemporal Substitution,' Journal of Political Economy, 110(4), pp. 825-853.

[27] Wolff, E.N. (2010) 'Recent Trends in Household Wealth in the United States: Rising Debt and the Middle-Class Squeeze - an Update to 2007', Levy Economics Institute Working Paper 589. 


\section{Appendix A: Numerical Simulation Procedure and Cali- bration}

\section{Baseline Simulation}

The complete model consists of households' and firms' first order optimization conditions, the budget constraints, the production function, the capital accumulation equation, the transversality conditions and the definitions of returns. The solution method follows Davig (2004) and is based on Coleman and Fenyes (1992). It conjectures candidate decision and pricing rules which allow to reduce the system to a set of expectational first-order difference equations. In our case, due to consecutive substitutions, we are able to reduce the system to only one conjectured decision rule, that for total (per capita) investment, denoted $I_{t}=I_{t}\left(K_{t-1}, \Delta z_{t}, \gamma_{t}^{c}\right)$. Dividing all equations by $\exp \left(z_{t-1}\right)$ and denoting the so transformed variables with atilde: $X_{t} \rightarrow \tilde{X}_{t}$, the system of equations is as follows:

$$
\begin{aligned}
& \tilde{C}_{t}^{w}=(1-\alpha)(1-\theta) \tilde{Y}_{t}+\tilde{B}_{t-1}^{c, w}-\left(\tilde{B}_{t}^{c, w} / R_{t}^{f}\right) \exp \left(\Delta z_{t}\right) \\
& \tilde{C}_{t}^{c}=\alpha(1-\theta) \tilde{Y}_{t}+D_{t}+\tilde{B}_{t-1}^{c, c}-\left(\tilde{B}_{t}^{c, c} / R_{t}^{f}\right) \exp \left(\Delta z_{t}\right) \\
& \tilde{C}_{t}=\tilde{Y}_{t}-\tilde{I}_{t}\left(\tilde{K}_{t-1}, \Delta z_{t}, \gamma_{t}^{c}\right) \\
& \tilde{D}_{t}=\theta \tilde{Y}_{t}-\tilde{I}_{t}\left(\tilde{K}_{t-1}, \Delta z_{t}, \gamma_{t}^{c}\right)-\mu \tilde{K}_{t-1}+\mu\left(\tilde{K}_{t} / R_{t}^{f}\right) \exp \left(\Delta z_{t}\right) \\
& \tilde{Y}_{t}=A\left(\left(N^{w}\right)^{1-\alpha}\left(N^{c}\right)^{\alpha}\right)^{1-\theta} \tilde{K}_{t-1}^{\theta} \exp \left((1-\theta) \Delta z_{t}\right) \\
& \tilde{K}_{t}=\left(1-\delta+G\left(\frac{\tilde{I}_{t}\left(\tilde{K}_{t-1}, \Delta z_{t}, \gamma_{t}^{c}\right)}{\tilde{K}_{t-1}}\right)\right) \tilde{K}_{t-1} \exp \left(-\Delta z_{t}\right) \\
& 1=\beta E_{t}\left(\frac{\left(\tilde{C}_{t+1}^{c} \tilde{C}_{t}^{c}\right)^{-\gamma_{t}^{c}}}{E_{t}\left(\tilde{C}_{t+1}^{c} \tilde{C}_{t}^{c}\right)^{-\gamma_{t}^{c}}} R_{t+1}^{k}\right) \\
& R_{t+1}^{k}=\frac{\tilde{D}_{t+1}+\frac{\left(1-G^{\prime}\left(\tilde{I}_{t+1} \tilde{K}_{t}\right) \mu / R_{t+1}^{f}\right)}{G^{\prime}\left(\tilde{I}_{t+1} \tilde{K}_{t}\right)} \tilde{K}_{t+1}}{\frac{\left(1-G^{\prime}\left(\tilde{I}_{t} \tilde{K}_{t-1}\right) \mu / R_{t}^{f}\right)}{G^{\prime}\left(\tilde{I}_{t} \tilde{K}_{t-1}\right)} \tilde{K}_{t}} \\
& \tilde{P}_{t}^{s}=\frac{\left(1-G^{\prime}\left(\tilde{I}_{t} \tilde{K}_{t-1}\right) \mu / R_{t}^{f}\right)}{G^{\prime}\left(\tilde{I}_{t} \tilde{K}_{t-1}\right)} \tilde{K}_{t}
\end{aligned}
$$




$$
\begin{gathered}
R_{t+1}^{s}=\frac{\tilde{P}_{t+1}^{s} \exp \left(\Delta z_{t}\right)+\tilde{D}_{t+1}}{\tilde{P}_{t}^{s}} \\
R_{t}^{f}=\beta^{-1} \\
R_{t+1}^{e}=R_{t+1}^{s}-R_{t}^{f} \\
\tilde{B}_{t}^{c, w}+\tilde{B}_{t}^{c, c}=\mu \tilde{K}_{t} \\
\tilde{B}_{t}^{c, c}=0 \\
G\left(\frac{\tilde{I}_{t}}{\tilde{K}_{t-1}}\right)=\frac{a_{1}}{1-1 \xi}\left(\frac{\tilde{I}_{t}\left(\tilde{K}_{t-1}, \Delta z_{t}, \gamma_{t}^{c}\right)}{\tilde{K}_{t-1}}\right)^{1-1 \xi}+a_{2} \\
G^{\prime}\left(\frac{\tilde{I}_{t}}{\tilde{K}_{t-1}}\right)=a_{1}\left(\frac{\tilde{I}_{t}\left(\tilde{K}_{t-1}, \Delta z_{t}, \gamma_{t}^{c}\right)}{\tilde{K}_{t-1}}\right)^{-1 \xi}
\end{gathered}
$$

This system is solved for every possible set of state variables over a discrete partition of the state space. The solution consists of a set of decision rules and pricing functions satisfying the above system. The solution method treats the state variables and the initially conjectured decision rules and pricing functions as given. Based on this, it is possible to compute the values of the remaining endogenous variables in any given state and for any realization of the shock. The expectations are computed by numerical quadrature. Given these, $\tilde{I}_{t}\left(\tilde{K}_{t-1}, \Delta z_{t}, \gamma_{t}^{c}\right)=\tilde{I}_{t}$ is treated as an unknown. The solution is then found by solving this equation ${ }^{14}$ in 1 unknown using Chris Sims' non-linear equation solver code csolve. ${ }^{15}$ The iteration procedure is repeated until the iteration improves the current decision rule at any given state vector by less than some tolerance level, which we set to $10^{-12}$.

\footnotetext{
${ }^{14}$ Specifically, this equation is the capital Euler equation (20).

${ }^{15}$ Available at http://sims.princeton.edu/yftp/optimize.
} 